\title{
DETERMINATION OF REGIONS SUITABLE FOR AGRICULTURE IN THE GORDON COSENS FOREST OF ONTARIO BY MEANS OF ANALYTICAL HIERARCHY PROCESS WITH FUZZY LOGIC INFERENCE
}

\author{
R. Pittman, B. Hu * G. Sohn \\ Dept. of Earth and Space Science and Engineering, York University, 4700 Keele Street, Toronto ON M3J 1P3 Canada \\ (rpittman, baoxin, gsohn)@yorku.ca
}

Commission III, WG III/10

KEY WORDS: Analytical Hierarchy Process, Fuzzy Logic Inference, Land Management, Soil Texture, ELC Moisture Regime

\begin{abstract}
:
Analytical Hierarchy Process (AHP) with fuzzy logic inference on attributes was employed to determine areas most suitable for agriculture in the Gordon Cosens Forest (GCF) region within the District of Cochrane in northern Ontario, Canada. Attribute layers considered were soil texture, ELC (Ecological Land Classification) moisture regime, slope, canopy height model (CHM), distance to existing road networks and distance to water bodies. Fuzzy logic inference was utilized to rescale the attributes to a normalized range, taking into account preferability, which was then subjected to pairwise comparisons via AHP to determine the attribute layers' weightings. For the study area, the localities identified as most compatible for agricultural development include the southeastern section of the GCF at approximately $30 \mathrm{~km}$ south of the community of Fauquier and the westernmost area of the GCF at about $10 \mathrm{~km}$ east of Mattice.
\end{abstract}

\section{INTRODUCTION}

There is emerging interest in land management studies for boreal biomes, due in part to expected environmental transitions resulting from climate change (Boulanger et al., 2017) as well as inventory purposes arising from the need to model soil properties of boreal environments and peatlands (Mansuy et al., 2014). The recent growth of digital soil mapping research (Minasny et al., 2019) has resulted in prediction maps of soil properties for certain boreal regions. Such predictive mapping results can be utilized for land management and environmental studies. Land management applications can include determining areas most suitable for agricultural activities, which can be warranted due to rising global food demand (Tilman et al., 2011). Prediction maps of soil properties such as texture (Walters et al., 1992) and moisture (Misra and Tyler, 1999) can relate to nutrient status and thus be of interest for determining land compatible for agriculture. For this analysis, soil attributes can be combined with other characteristics deemed essential for agricultural land suitability, which often correspond to slope and accessibility considerations (Grau et al., 2013).

The aggregation of attributes from various models or measurements is not necessarily a trivial matter for decisionmakers when employing subsequent analysis results. Experts of the related subject matter can frequently determine what attributes or predictors are most important for decision analysis for many applications. If just one attribute is considered, the subsequent analysis can be straightforward for deciding what quantities of that attribute are more or less desirable for the application of interest. However, it can be challenging to quantify weightings to multiple attributes or justify an evaluation in an orderly manner. Such a weighting system should be intuitive to interpretation but not appear arbitrary, and hence systematic in execution.

Analytical Hierarchy Process (AHP) is a method by which different attributes can be integrated for resolving the allocations of the relative weightings (Wang et al., 2009) and can be applied to determine areas suitable for agriculture (Akinci et al., 2013; Sari and Koyuncu, 2021). AHP determines the weightings using pairwise comparisons between the criteria attributes, evaluated on a consistent ordinal scale. The pairwise comparisons facilitate the ease of deciding the importance among attributes, as each attribute is compared individually to other criteria attributes. To incorporate the various attributes, each attribute considered needs to be rescaled to a normalized range to quantify the weightings' influence.

Just as the resolution of weightings between the various criteria attributes may not appear as trivial, the normalizing of each attribute layer to an equivalent scale in a rational way can be a challenge. Fuzzy logic can be utilized to regularize each attribute layer to a normalized scale by a means that is intuitive for decision-makers, which can be exploited by AHP (Kannan et al., 2013; Karimi, A. R.; Mehrdadi. N.; Hashemian, S. J.; Nabi Bidhendi, G. R.; Tavakkoli Moghaddam, 2011; Pourghasemi et al., 2012). The fuzzy logic inference relies on a transition between margins of an attribute, which depends on thresholds for which attribute values are considered satisfactory or unsatisfactory. Such normalization can emerge less arbitrary and more useful than an ordinal rating for the attribute values, as fuzzy logic

\footnotetext{
Corresponding author
} 
inference can better relate to the extents of attribute fittingness that are sensible to decision-makers.

AHP with fuzzy logic inference was employed to determine localities suitable for agriculture in a boreal study area in northern Ontario by applying attributes resolved by digital soil mapping and other attributes corresponding to criteria of significance. This implementation of the AHP method with fuzzy logic inference is discussed in this paper.

\section{STUDY AREA AND ATTRIBUTE DATA}

The targeted study area corresponds to the Gordon Cosens Forest (GCF) in the District of Cochrane in Ontario (ON), Canada. This region encompasses approximately $2570 \mathrm{~km}^{2}$ and is bounded by the latitudes of $49.0^{\circ} \mathrm{N}$ to $49.7^{\circ} \mathrm{N}$ and the longitudes of $81.9^{\circ} \mathrm{W}$ to $83.4^{\circ} \mathrm{W}$. Topography for this region is relatively flat, with elevations ranging from a minimum of $197 \mathrm{~m}$ in the north to a maximum of $284 \mathrm{~m}$ in the south, with steep slopes occurring along sections of the riverbanks. There are three main rivers that each transverse through this area on a northward trajectory: the Groundhog, Kapuskasing and Missinaibi rivers, respectively, ranging from east to west. The largest community in this region is Kapuskasing, situated in the center of the study area. This region encompasses the boreal biome and is mostly forested with the dominant tree species of black spruce (Picea mariana), white spruce (Picea glauca), balsam fir (Abies balsamea) and trembling aspen (Populus tremuloides). There are tracts of agricultural land around the community of Kapuskasing and eastwards near the communities of Moonbeam and Fauquier. This study region is depicted in Figure 1, which also consists of true-color composite imagery generated from median satellite reflectance from Landsat- 8 for cloud-free (less than $1 \%$ clouds) scenes from June and July of 2018. In this composite image, the bands B2 $(0.452-0.512 \mu \mathrm{m}), \mathrm{B} 3(0.533-0.590 \mu \mathrm{m})$ and B4 $(0.636-0.673 \mu \mathrm{m})$ were taken for blue, green and red, respectively. Note that the grid coordinates outlining the figure are in the NAD 1983 Lambert conformal conic projection.

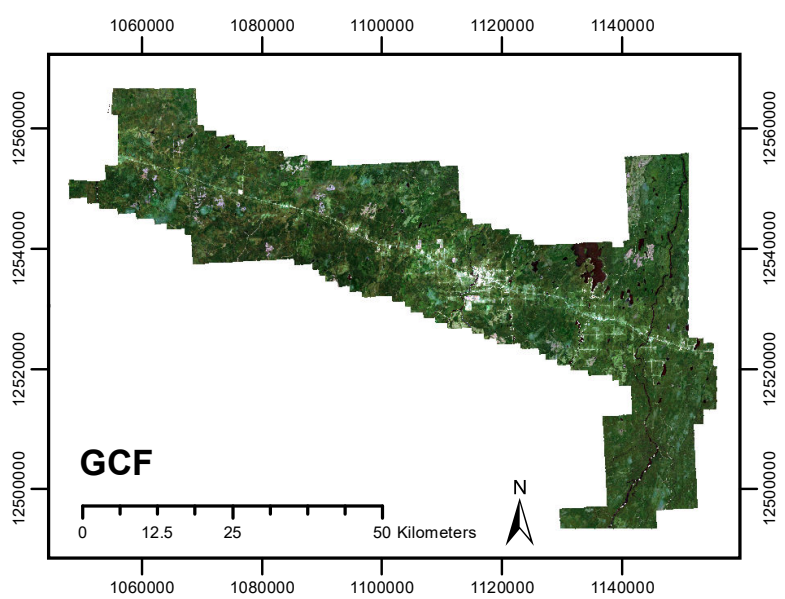

Figure 1 . The study area for determining agriculture suitability for the GCF in the District of Cochrane, ON.

Six attributes were considered for determining the suitability of regions for agriculture, which corresponded to criteria of soil nutrient properties, slope, accessibility, wetness, and environmental impact. Mechanized agriculture is generally confined to localities of well-drained fertile soil with flat slopes (Grau et al., 2013). Furthermore, areas of varying topography or with poorly-drained soils often accommodate high biodiversity value (Grau et al., 2013), and hence should be sustained for forest conservation. For this analysis, attributes corresponding to soil properties included prediction maps for texture family and ELC (Ecological Land Classification) moisture regime (Pokharel and Dech, 2011). The main soil textures present in the GCF region are clayed, loamy and peat. ELC moisture regime classifications are rated on an ordinal scale; these range from 0 for dry, 1, 2 and 3 for fresh, 4 and 5 for moist, 6 for very moist, and 7, 8 and 9 for wet. An attribute for accessibility included distances to existing road networks (Statistics Canada, 2017) to correspond to distance from existing infrastructure. To avoid flooding from spring snowmelt, distances to water bodies were considered as an attribute for wetness. Water bodies were determined from JAXA PALSAR imagery (Shimada et al., 2014) from 2017. Other attributes considered included slope for determining level land for farm machinery derived from a digital elevation model (DEM). A canopy height model (CHM) was also included, as it can conform to an accessibility attribute regarding the difficulty required for clearing land. $\mathrm{CHM}$ also relates to environmental impact as $\mathrm{CHM}$ corresponds to vegetation density, linked to species biodiversity (Tscharntke et al., 2005) considerations. Both the DEM and CHM were derived from LiDAR data retrieved during 2016 and 2017, obtained from the Ontario Ministry of Natural Resources and Forestry. All the attributes employed for this analysis are depicted in Figure 2.

\section{METHODOLOGY}

Fuzzy logic inference was implemented to normalize the attribute data to a common scale between 0 and 1 , with 0 denoting least preferability and 1 denoting most preferability. The maps for the fuzzy logic inference of the various attribute layers are shown in Figure 3.

For soil texture, loamy and clayed soils are suitable for cropland agriculture (Dexter, 2004), and for this analysis were assigned 1 for clayed and loamy, and 0 assigned for peat. The peat areas were considered undesirable for agriculture, as these areas also have wet ELC moisture regimes as can be attested in Figure 2. The ELC moisture regimes were rescaled based upon:

$$
\text { ELC Moisture Regime }_{\text {Fuzzy }}=\frac{\text { ELC Moisture Regime }}{9}
$$

As the GCF is heavily forested and agricultural land generally needs to be cleared for usage, the most preferred is towards choosing areas with the least vegetation. There are also environmental impact considerations, which entail the need to maintain as much of established and old-growth forest as possible for species health. CHM was rescaled on the following scaling:

$$
\text { CHM }_{\text {Fuzzy }}=\left\{\begin{array}{r}
\frac{25-C H M}{25}, \text { if } C H M \leq 25[\mathrm{~m}] \\
0, \text { if } C H M>25[\mathrm{~m}]
\end{array}\right.
$$

Although the GCF region is relatively flat, slope needs to be incorporated when evaluating land suitability for cropland 
agriculture as farm machinery requires land of gentle slopes for operation. Slopes less than $5 \%$ were considered acceptable, whereas slopes greater than $5 \%$ were deemed too steep for driving farm equipment:

$$
\text { Slope }_{\text {Fuzzy }}=\left\{\begin{array}{r}
\frac{5-\text { Slope }}{5}, \text { if Slope } \leq 5[\%] \\
0, \text { if Slope }>5[\%]
\end{array}\right.
$$

As excess surface moisture is an issue in the GCF region in part due to the wetter ELC moisture regimes, and snowmelt does not generally occur until the end of winter, it is preferable to have farmland that is not too close to rivers or lakes. A distance of $2 \mathrm{~km}$ was regarded as safe from spring flooding:

$$
\text { Water }_{\text {Fuzzy }}=\left\{\begin{array}{r}
\frac{2000-\text { Water }}{2000}, \text { if Water } \leq 2000[\mathrm{~m}] \\
1, \text { if Water }>2000[\mathrm{~m}]
\end{array}\right.
$$

Distances to existing road networks were also considered, as it requires less effort to clear land closer to existing road networks. As well, it is preferable to have land closer to prevailing communities and other associated infrastructure. Distances greater than $20 \mathrm{~km}$ were deemed as too far away for being desirable for agriculture potential:

$$
\text { Roads }_{\text {Fuzzy }}=\left\{\begin{array}{r}
\frac{20000-\text { Roads }}{20000}, \\
\text { 0, if } \text { Roads } \leq 20000[\mathrm{~m}] \\
\text { Roads }>20000[\mathrm{~m}]
\end{array}\right.
$$
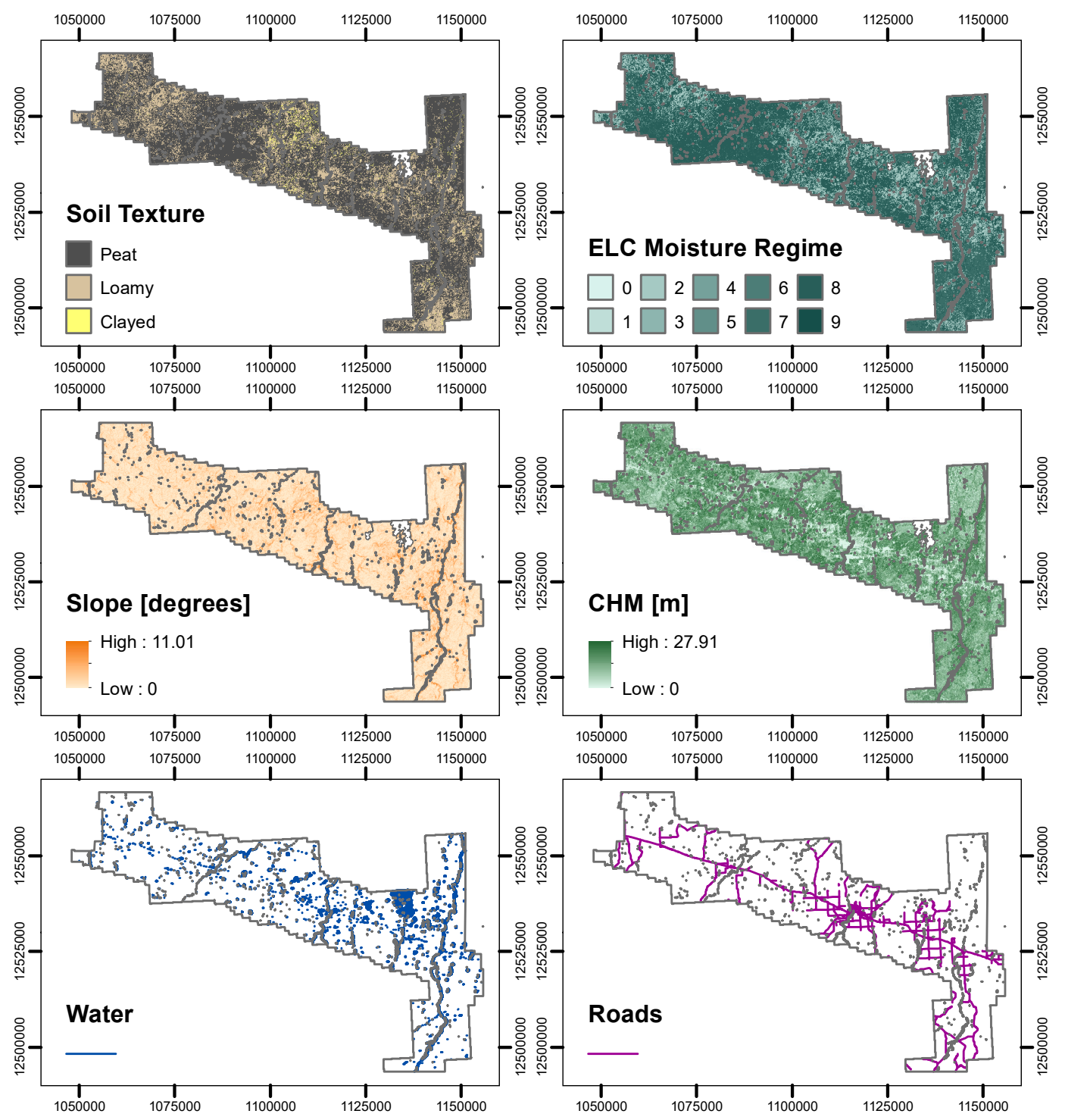

Figure 2. Attribute layers considered for agriculture suitability analysis.

AHP was employed to determine weightings for the attribute layers. A three-step process ensued. For Step I, ordinal scale scores ranging from 1 to 5 were applied for the pairwise comparisons; here, among the comparisons, 1 denoted equal importance, 2 denoted moderate importance, 3 denoted strong importance, 4 denoted very strong importance, and 5 denoted extreme importance. The attribute layers were first ranked in order from the most important, following to least important. Once that was completed, then pairwise comparisons using the aforementioned 5 ordinal scale scores were completed. Note that an attribute would have pairwise equal importance with itself (signified by 1), with an inverse ranking applied for the 
reverse order of pairwise comparison; this forms the consistency matrix. For Step II, the pairwise comparison scores were normalized by their respective column sum calculated in Step I; wherein Step III, the final weightings were determined as the average of each row of entries of the normalized scores from Step II. Note that a consistency index was calculated to evaluate the consistency of ratings among the attributes. Consistency index (CI) was defined as:

$$
C I=\frac{\lambda-n}{n-1}
$$

where $\lambda=$ largest eigenvalue of consistency matrix

\section{$n=$ number of attributes}

A value of 0 for the CI denotes complete consistency, with larger values indicating more inconsistency. Eigenvalues were computed from the consistency matrix determined in Step I of Table 1, where the largest eigenvalue from this set of eigenvalues was utilized for calculating the CI. For this analysis, a CI value within $10 \%$ of perfect consistency, that is less than 0.1, was considered satisfactory (Karimi, A. R.; Mehrdadi. N.; Hashemian, S. J.; Nabi Bidhendi, G. R.; Tavakkoli Moghaddam, 2011; $\mathrm{Wu}$ and $\mathrm{Xu}, 2012$ ).


Figure 3. Attribute layers renormalized to common scale via fuzzy logic inference. Note that 0 denotes the least preferability, whereas 1 denotes the most preferability.

\section{RESULTS AND ANALYSIS}

The pairwise comparisons among the attributes for Step I, intermediate calculations in Step II and weightings from Step III for the AHP are reported in Table 1. The distance to existing road networks was ranked as the most important attribute, followed in order by soil texture family, ELC moisture regime, slope, CHM, and distances to water bodies ranked as the least important attribute. The CI for the rankings was calculated as 0.0325 , which indicates that the pairwise comparisons performed for Step I in Table 1 were sufficient for consistency purposes. 
Prediction maps for regions suitable for agriculture in the GCF region are displayed in Figure 4. Note that the results from the AHP weightings are denoted in the top figure. In contrast, all fuzzy logic inference attribute layers (i.e., all layers considered equal) are shown in the bottom figure. These figures' intensities range from 0 for least suitability to 1 indicating most suitability for agriculture. From Figure 4, one can verify that existing agricultural land is ranked as high suitability, as seen from the center of the true-color composite image (near the community of Kapuskasing) from Figure 1, which substantiates this analysis.

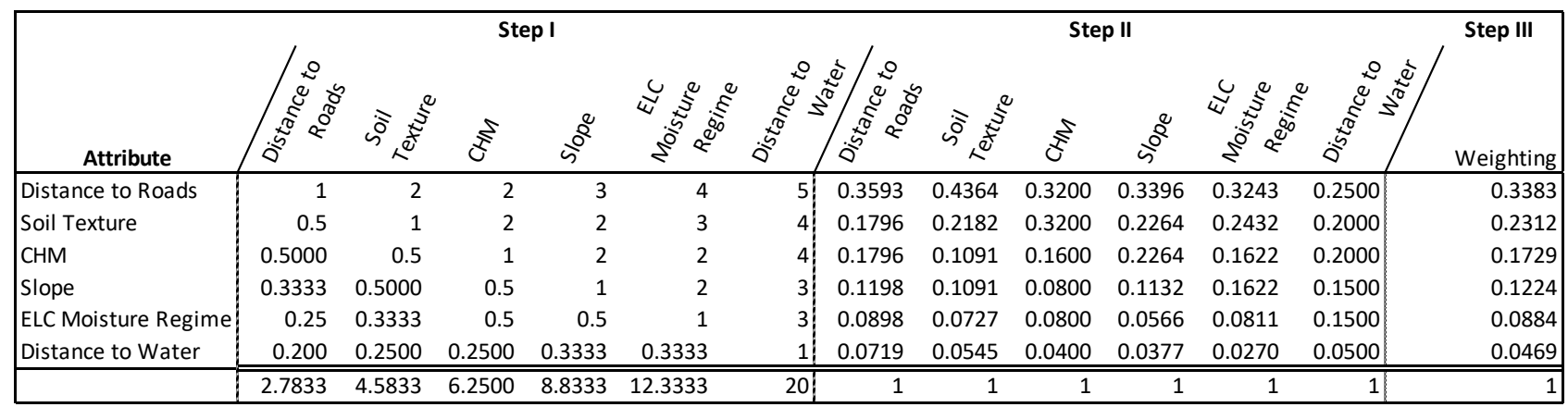

Table 1. Steps of AHP for determining weightings for attribute layers.

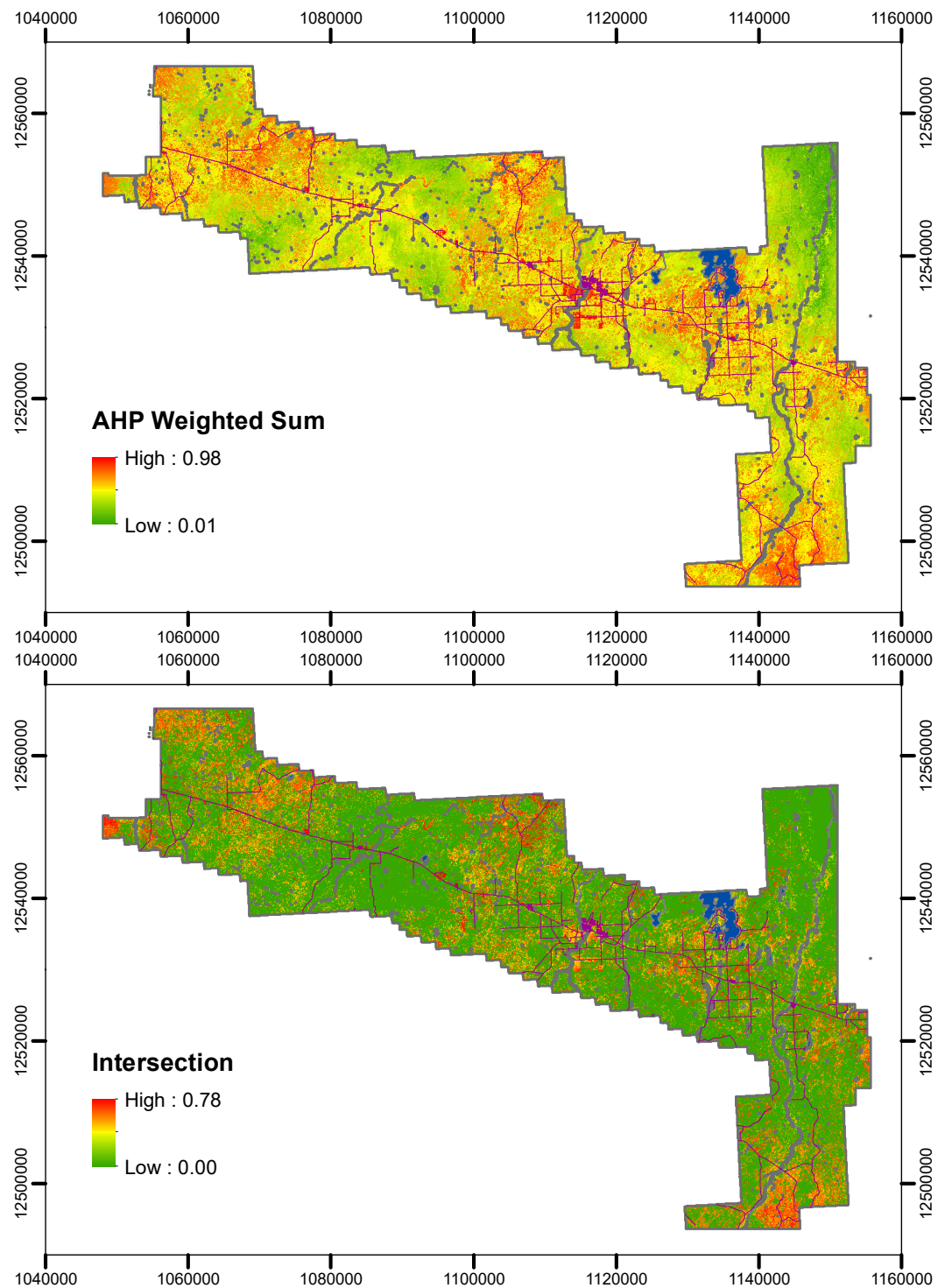

Figure 4. Areas most suitable for agriculture (as indicated in orange), with AHP weighting solution (top), and outcome with all attribute layers considered with equal weighting (bottom). 
Regions compatible for agriculture correspond to regions close to existing road networks with either loamy or clayed soil of drier moisture regimes, with minimal slopes and preferably of the least canopy height possible. From Figure 4, it can be ascertained that there are suitable localities for agriculture in the southeast of the GCF region at approximately $30 \mathrm{~km}$ south of the community of Fauquier (with false easting near $1,140,000 \mathrm{~m}$ and false northing near $12,500,000 \mathrm{~m}$ ) and also to the western part of the region at approximately $10 \mathrm{~km}$ east of the community of Mattice (west of false easting of 1,080,000 $\mathrm{m})$. The regions of least compatibility for agriculture correspond to rivers and wetlands, as attested in Figure 1, which would pose the most difficulty for clearing and preparing for agricultural development.

From Figure 4, even when all attribute layers were weighted equally for the AHP (here denoted by the intersection), similar localities were highlighted as being the most preferable for agriculture development. This outcome demonstrates that this analysis is not sensitive to perturbations with the different attribute layers' weightings. Accordingly, there can be confidence with the identification of suitable agricultural localities.

\section{DISCUSSION}

AHP with fuzzy logic inference can systematically lead to a solution for determining suitable areas for agricultural development. For this analysis, agricultural development was assumed to be of a practice similar to what has previously existed for the GCF region, which would consist of approximately 40 hectare field plots devoted to either pasture or cropland agriculture. Pastures would correspond to hay crops, and cropland crops would likely comprise either barley (Hordeum vulgare), oats (Avena sativa) or canola (Brassica napus).

With the AHP, a five-point ordinal scale scoring was employed for this analysis. This scale was arbitrarily chosen, but valid as long as a consistent rating scheme was utilized throughout for all pairwise comparisons of the attribute layers. The goal of AHP is to yield a methodical decision analysis that can be analytically justified instead of just based solely upon haphazard reasoning. AHP can guide land management decisions founded upon the results of scientific models or observations, which can be adapted for policy purposes.

The most compatible regions for agriculture would vary depending on what criteria and corresponding attributes that decision-makers would deem imperative. As excess soil moisture is a concern for the District of Cochrane in northern Ontario, and existing agricultural fields require tile drainage to remove soil water (Personal communication with farmers near Kapuskasing ON), for this region, the drier the land, the more preferable. However, this could contrast with what would be desired for other types of biomes. The highest ELC moisture regime ratings correspond to wet soil conditions, which occur in the wetland environments and overwhelmingly have peat as the soil texture (Figure 2). For this region, areas with peat would not be selected for agricultural development. As peatland environments are sensitive to environmental change (Minasny et al., 2019), it is best to avoid transforming wetland regions.
As clearing land and building road networks can be expensive, it is preferable to convert land close to existing infrastructure. Some of the established roadways would correspond to logging roads, and it is likely that if settled, then the road network would be resurveyed to conform to the grids of a prevailing land survey system. Nonetheless, existing roads and approaches would have to be utilized first to send equipment into a locality to prepare a new road network and construct new infrastructure.

JAXA PALSAR imagery from 2017 for L-band SAR was exploited to detect water bodies, arising from a previous analysis. The results of this investigation were compared to hydrographic vector file output obtained from Statistics Canada (Statistics Canada, 2016) for the region and matched fittingly. It was decided to utilize the results resolved from PALSAR imagery, as it was presumed this would be more accurate in better delineating boundaries and determining minor bodies of water. The intention was to resolve the greater bodies of water that could be prone to flooding and not small-scale localized flooding that would correspond with minor streams or sloughs within a field. Tile drainage within fields can remedy flooding associated with small-scale sloughs.

CHM was applied as an attribute relating to the extent of potential environmental impact, as CHM corresponds to vegetation density. An objective of any land management study should be to minimize disadvantages so as to maintain or even restore the condition of the present ecosystem. For future studies, a more thorough environmental impact investigation should be undertaken to determine trade-offs between conservation and agricultural development (Grau et al., 2013).

\section{CONCLUSION}

AHP was able to systematically determine areas in the GCF most compatible for agriculture. The fuzzy logic inference on the attributes facilitated the specification of preferable ranges for the attributes that better pertained to expert subject matter knowledge. This integration with the AHP led to an analysis that was both intuitive and methodological.

The most suitable areas identified for agricultural development within the GCF region occur in the southeasternmost region and westernmost regions of the GCF target area. These localities would correspond to approximately $30 \mathrm{~km}$ south of the community of Fauquier and about $10 \mathrm{~km}$ east of the community of Mattice. Current agricultural lands had high desirability for agriculture, which is reasonable for assessment purposes for the analysis. A combination of soil properties, slope and accessibility attributes can determine the localities most suitable for cropland agriculture. The pairwise comparison ratings utilized for this evaluation had a consistent CI, with accessibility and soil texture rated as among the most importance attributes for this analysis.

\section{ACKNOWLEDGEMENTS}

The slope was generated from a DEM in SAGA GIS (SAGA Development Team, 2020) software. The DEM and CHM attributes were derived from LiDAR data obtained via Land 
Information Ontario from the Ontario Ministry of Natural Resources and Forestry. The soil texture and ELC moisture regime attributes were generated based upon site data obtained from the Ontario Forestry Resource Inventory. The road network files were obtained from Statistics Canada as part of the Road Network File (Catalogue no. 92-500-X). JAXA PALSAR and Landsat- 8 imagery were obtained from Google Earth. ArcMap 10.6 software from Esri was utilized for generating the figures in this paper.

Funding for this study was provided by the Ontario Ministry of Agriculture, Food and Rural Affairs (OMAFRA) as well as through a Discovery Grant awarded to Dr. Baoxin Hu from the Natural Sciences and Engineering Research Council (NSERC) of Canada.

\section{REFERENCES}

Akinci, H., Özalp, A.Y., Turgut, B., 2013. Agricultural land use suitability analysis using GIS and AHP technique. Comput. Electron. Agric. 97, 71-82. doi.org/10.1016/j.compag.2013.07.006

Boulanger, Y., Taylor, A.R., Price, D.T., Cyr, D., McGarrigle, E., Rammer, W., Sainte-Marie, G., Beaudoin, A., Guindon, L., Mansuy, N., 2017. Climate change impacts on forest landscapes along the Canadian southern boreal forest transition zone. Landsc. Ecol. 32, 1415-1431. doi.org/10.1007/s10980-016-0421-7

Dexter, A.R., 2004. Soil physical quality: Part I. Theory, effects of soil texture, density, and organic matter, and effects on root growth. Geoderma 120, 201-214. doi.org/10.1016/j.geodermaa.2003.09.005

Grau, R., Kuemmerle, T., Macchi, L., 2013. Beyond "land sparing versus land sharing": Environmental heterogeneity, globalization and the balance between agricultural production and nature conservation. Curr. Opin. Environ. Sustain. 5, 477483. doi.org/10.1016/j.cosust.2013.06.001

Kannan, D., Khodaverdi, R., Olfat, L., Jafarian, A., Diabat, A., 2013. Integrated fuzzy multi criteria decision making method and multiobjective programming approach for supplier selection and order allocation in a green supply chain. $J$. Clean. Prod. 47, 355-367. doi.org/10.1016/j.jclepro.2013.02.010

Karimi, A. R.; Mehrdadi. N.; Hashemian, S. J.; Nabi Bidhendi, G. R.; Tavakkoli Moghaddam, R., 2011. Selection of Wastewater Treatment Process Based on Analytical Hierarchy Process. Int. J. Civ. Eng. Technol. 5, 27-33.

Mansuy, N., Thiffault, E., Paré, D., Bernier, P., Guindon, L., Villemaire, P., Poirier, V., Beaudoin, A., 2014. Digital mapping of soil properties in Canadian managed forests at $250 \mathrm{~m}$ of resolution using the k-nearest neighbor method. Geoderma 235-236, 59-73. doi.org/10.1016/j.geoderma.2014.06.032

Minasny, B., Berglund, Ö., Connolly, J., Hedley, C., de Vries, F., Gimona, A., Kempen, B., Kidd, D., Lilja, H., Malone, B., McBratney, A., Roudier, P., O'Rourke, S., Rudiyanto, Padarian, J., Poggio, L., ten Caten, A., Thompson, D., Tuve, C., Widyatmanti, W., 2019. Digital mapping of peatlands - A critical review. Earth-Science Rev. 196, 102870. doi.org/10.1016/j.earscirev.2019.05.014

Misra, A., Tyler, G., 1999. Influence of soil moisture on soil solution chemistry and concentrations of minerals in the calcicoles Phleum phleoides and Veronica spicata grown on a limestone soil. Ann. Bot. 84, 401-410. doi.org/10.1006/anbo.1999.0941

Pokharel, B., Dech, J.P., 2011. An Ecological Land Classification approach to modeling the production of forest biomass. For. Chron. 87, 23-32. doi.org/10.5558/tfc87023-1

Pourghasemi, H.R., Pradhan, B., Gokceoglu, C., 2012. Application of fuzzy logic and analytical hierarchy process (AHP) to landslide susceptibility mapping at Haraz watershed, Iran. Nat. Hazards 63, 965-996. doi.org/10.1007/s11069-0120217-2

SAGA Development Team, 2020. System for Automated Geoscientific Analysis (SAGA).

Sari, F., Koyuncu, F., 2021. Multi Criteria Decision Analysis To Determine the Suitability of Agricultural Crops for Land Consolidation Areas. Int. J. Eng. Geosci. 6, 64-73. doi.org/10.26833/ijeg.683754

Shimada, M., Itoh, T., Motooka, T., Watanabe, M., Shiraishi, T., Thapa, R., Lucas, R., 2014. New global forest/non-forest maps from ALOS PALSAR data (2007-2010). Remote Sens. Environ. 155, 13-31. doi.org/10.1016/j.rse.2014.04.014

Statistics Canada, 2017. Road Network File, Reference Guide 92-500-G. Ottawa, Ontario. doi.org/ISSN 1911-5210

Statistics Canada, 2016. Boundary Files, Reference Guide 92160-G. Ottawa, Ontario.

Tilman, D., Balzer, C., Hill, J., Befort, B.L., 2011. Global food demand and the sustainable intensification of agriculture. Proc. Natl. Acad. Sci. U. S. A. 108, 20260-20264. doi.org/10.1073/pnas.1116437108

Tscharntke, T., Klein, A.M., Kruess, A., Steffan-Dewenter, I., Thies, C., 2005. Landscape perspectives on agricultural intensification and biodiversity - Ecosystem service management. Ecol. Lett. 8, 857-874. doi.org/10.1111/j.14610248.2005.00782.x

Walters, D.T., Aulakh, M.S., Doran, J.W., 1992. Effects of Soil Aeration, Legume Residue, and Soil Texture on Transformations of Macronutrients and Micronutrients in Soils. Soil Sci. 153, 100-107. doi.org/10.1097/00010694199202000-00003

Wang, J.J., Jing, Y.Y., Zhang, C.F., Zhao, J.H., 2009. Review on multi-criteria decision analysis aid in sustainable energy decision-making. Renew. Sustain. Energy Rev. 13, 2263-2278. doi.org/10.1016/j.rser.2009.06.021

Wu, Z., Xu, J., 2012. A consistency and consensus based decision support model for group decision making with multiplicative preference relations. Decis. Support Syst. 52, 757-767. doi.org/10.1016/j.dss.2011.11.022 